\title{
Oxamniquine, praziquantel and lovastatin association in the experimental Schistosomiasis mansoni
}

\author{
Neusa Araújo/ ${ }^{+}$, Ana Carolina Alves de Mattos, Ana Karine Sarvel $/{ }^{1}$, Paulo Marcos Zech Coelho/ ${ }^{1}$, \\ Naftale Katz/ ${ }^{1}$
}

Laboratório de Esquistossomose, Instituto René Rachou-Fiocruz, Av. Augusto de Lima 1715, 30190-002 Belo Horizonte, MG, Brasil

${ }^{1}$ Santa Casa de Belo Horizonte, Belo Horizonte, Brasil

The activity of lovastatin associated with oxamniquine or praziquantel against schistosomiasis mansoni was evaluated in mice infected with Schistosoma mansoni. Forty days after infection, mice were treated with lovastatin, $400 \mathrm{mg} / \mathrm{kg}$ for five consecutive days by oral route, and on the last day of this sequence with $50 \mathrm{mg} / \mathrm{kg}$ oxamniquine or with $200 \mathrm{mg} / \mathrm{kg}$ praziquantel, both by oral route, single dose. Fifteen days later, the animals were perfused in parallel with an untreated control group. Studies were carried out in vitro, using lovastatin in culture medium containing S. mansoni worms proceeding from experimentally infected mice. In the in vivo trials, the association of lovastatin with oxamniquine or praziquantel did not show any additive action, but there were oogram changes when lovastatin was associated with oxamniquine. In vitro lovastatin was able to interrupt the maturation of S. mansoni eggs, which remained at the 1st or 2nd stages, depending on the dose used. The total number of morphologically dead eggs found in culture of worms exposed to $2 \mu \mathrm{g} / \mathrm{ml}$ or $4 \mu \mathrm{g} / \mathrm{ml}$ concentrations of lovastatin was significantly higher than the number of viable eggs. Using the probe Hoescht 33258 it was observed that $70 \%$ of the eggs considered morphologically viable in the treated groups (against 16\% in the control group) were labeled, indicating that the majority of the viable eggs had membrane permeability increased due to lovastatin action.

Key words: Schistosoma mansoni - lovastatin - drug association

In practice, chemotherapy is the main measure utilized for the control of schistosomiasis in endemic countries. The schistosomicidal drugs used, oxamniquine and praziquantel, present few side effects and a high schistosomicidal activity, thus contributing for the treatment of infection, as well as for the control of morbidity and transmission of the disease. In the 1970s, oxamniquine was very used for individual and mass treatment of schistosomiasis, presenting satisfactory results regarding efficacy and tolerance (Katz 1980). At the end of that decade, praziquantel became available for the treatment of schistosomiasis, showing good therapeutic activity and also few side effects as well. Praziquantel is now the drug of choice for the treatment of the disease caused by the three main species of the parasite that infect humans (Doenhoff et al. 2002). Taking into account the possible rise of resistance to treatment, the tolerance level of the worm to the drug, and the therapeutic failures, it is very important to search for new therapeutic alternatives for schistosomiasis. This search is now imperative, especially considering the possible interruption of oxamniquine production as a result of its higher cost, when compared to praziquantel.

The association of different drugs for use in the therapeutics of various infectious diseases can serve as a mechanism to avoid, or to delay, the rise of drug resistance.

Financial support: FIOCRUZ and FAPEMIG

+Corresponding author: araujon@cpqrr.fiocruz.br

Received 27 January 2008

Accepted 4 July 2008
In the present study, in vivo and in vitro trials were carried out on the efficacy of the treatment with lovastatin against the Schistosoma mansoni adult worms, when administered in association with oxamniquine or praziquantel in the mouse model.

\section{MATERIALS AND METHODS}

Experimental chemotherapy - Swiss mice (weighting $20 \mathrm{~g}$ on average), infected with $100 \pm 10 \mathrm{~S}$. mansoni cercariae (LE strain), by subcutaneous route, were used. The guidelines of the Ethical Committee for the use of experimental animals of the Fiocruz were followed. Forty days post infection (pi), groups of animals were treated with $400 \mathrm{mg} / \mathrm{kg} / \mathrm{day}$, oral route lovastatin (Mevacor ${ }^{\circledR}$, Merck Sharp \& Dohme), for five consecutive days, and on the last day with a single oral dose of $50 \mathrm{mg} / \mathrm{kg}$ oxamniquine or a single oral dose of $200 \mathrm{mg} / \mathrm{kg}$ praziquantel. The animals were sacrificed by cervical fracture, and perfused 15 days after the end of treatment. The same procedures were used for the control group, which was comprised of infected and untreated mice (Pellegrino \& Siqueira 1956). The female worms were observed with an optical microscope to observe the presence of eggs. The eggs in various stages of maturity were studied using the oogram pattern (Pellegrino et al. 1962).

In vitro trials - Mice infected with $S$. mansoni cercariae were sacrificed using sodium pentobarbital 3\% (300 $\mu \mathrm{l} / \mathrm{mice}$ ), and perfused according to the technique by Smithers and Terry (1965). The worms obtained were distributed into a 6 -well-plaque (4 worm pairs/well), and maintained in culture medium RPMI-1640 supplemented with $5 \%$ fetal bovine serum, $100 \mu \mathrm{g} / \mathrm{ml}$ penicillin and 
$100 \mu \mathrm{g} / \mathrm{ml}$ streptomycin. The worms were exposed to lovastatin, diluted in culture medium RPMI-1640, at the concentrations of $0.5 \mu \mathrm{g} / \mathrm{ml}, 1.2 \mu \mathrm{g} / \mathrm{ml}$ and $4 \mu \mathrm{g} / \mathrm{ml}$ for $24 \mathrm{~h}$, and kept in an incubator at $37^{\circ} \mathrm{C}$ and $5 \% \mathrm{CO}_{2}$. Afterwards, the worms were washed with culture medium, and maintained under the same conditions, without addition of the drug. Simultaneously, a control group was organized with worms that had been maintained under the same conditions, except for the presence of drug. Using an inverted microscope, observations were performed, and daily photos were taken from $24 \mathrm{~h}$ up to seven days after the beginning of culture. The culture medium was changed on alternate days.

Analysis of egg viability - The eggs obtained in culture were stained with the probe Hoescht 33258, at the concentration of $1 \mathrm{mg} / \mathrm{ml}$. For each milliliter of culture medium with eggs, $10 \mu \mathrm{l}$ of the probe was added. Slides were then prepared and observed under fluorescent microscope (K-Zeiss), using magnification of 10 and 40 times, for an 8-day-culture period (Sarvel et al. 2006).

In vitro/in vivo trials - The worms obtained from mice treated with lovastatin $(400 \mathrm{mg} / \mathrm{kg} /$ day for 5 days) and sacrificed three days after the end of treatment were cultured in vitro (in vivo/in vitro trials) in parallel with a group of worms exposed to $4 \mu \mathrm{g} / \mathrm{ml}$ lovastatin in vitro, as well as with a control group (worms not exposed to drug).

Analysis of data - The Student's $t$ test, the chi-square test or the analysis of variance, with the significance level of $p \geq 0.05$ were applied.

\section{RESULTS}

The results obtained in $S$. mansoni-infected mice treated with $400 \mathrm{mg} / \mathrm{kg}$ lovastatin, for five consecutive days, starting on the 40th day pi, associated with $50 \mathrm{mg} /$ $\mathrm{kg}$ oxamniquine or $200 \mathrm{mg} / \mathrm{kg}$ praziquantel, single oral dose administered on the last day of treatment can be seen in Table. The percentage of worms in the group of animals treated with lovastatin was distributed as follows: $86.4 \%$ in the mesentery, and $13.6 \%$ in the liver. In the group treated with oxamniquine, these values, were $49.1 \%$ in the mesentery and $50.9 \%$ in the liver. In the group treated with lovastatin and oxamniquine in association, $30.6 \%$ and $69.4 \%$ of the worms were recovered from the mesentery and liver, respectively. When the animals were treated with oxamniquine or with oxamniquine/lovastatin in association, the mortality rates of the worms were $43.6 \%$ and $60.3 \%$, respectively. No significant difference has been observed in these results. As far as the oogram change is concerned, the value increased from $75.0 \%$ (oxamniquine administered alone) to $92.3 \%$ (when oxamniquine and lovastatin were administered in association) $(\mathrm{p}>0.05)$. When praziquantel was administered, the mortality of parasites was $45.1 \%$ with oogram changes giving a value of $54.5 \%$ in comparison when it was administered associated with lovastatin (36.7\% worm mortality; $57.1 \%$ oogram changes). The percentage of worms in the group of animals treated with praziquantel was distributed as follows: $49.5 \%$ from the mesentery, and $50.5 \%$ from the liver. When

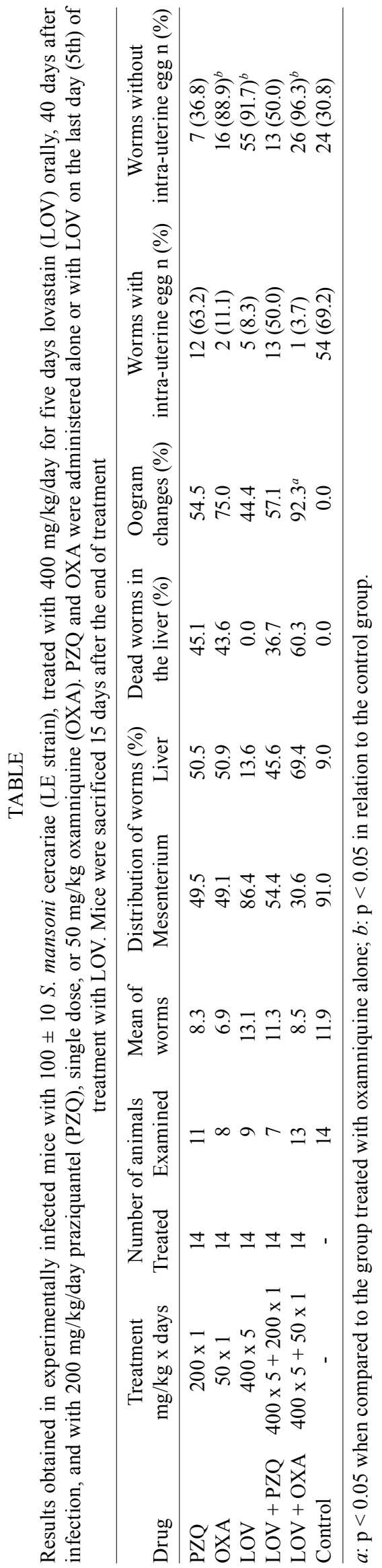


the animals were treated with the association of praziquantel and lovastatin the percentages were $54.4 \%$ dead worms in the mesentery, and $45.6 \%$ in the liver. The differences were not statistically significant. The group of animals treated with lovastatin alone presented $44.4 \%$ of oogram changes (a statistically significant result, when compared with the control group), with dead worms in the liver, and with a worm distribution in the mesentery and liver similar to that of the control group.

The number and respective percentage of female worms presenting intra-uterine egg in the different groups are in Table. When the three drugs were administered alone, lovastatin and oxamniquine presented a great activity regarding the cessation of oviposition (absence of intra-uterine egg). In fact, 91.7\% and 88.9\% of $S$. mansoni females treated with lovastatin or oxamniquine did not show any intra-uterine eggs, a significant result when compared to $30.8 \%$ of the control group $(\mathrm{p}<0.05)$. As regard praziquantel, no difference could be detected when compared to the control group. When lovastatin was used in association with oxamniquine or praziquantel, it was observed that the number of females without intra-uterine eggs varied from $36.8 \%$ to $50 \%$ (praziquantel association), and from $88.7 \%$ to $96.3 \%$ (oxamniquine association), but the differences were not significant, i.e., there was no additive or synergistic action as a result of the association of these drugs.

In vitro trials - The worms exposed to lovastatin, at any drug concentration, did not show any morphological change under observation using an inverted microscope, using 100X magnification. The tegument was found to be apparently complete, and the worm motion similar to that of the control group. Eggs could be seen in all the groups. However, the eggs laid by worms exposed to lovastatin did not develop throughout the experiment,

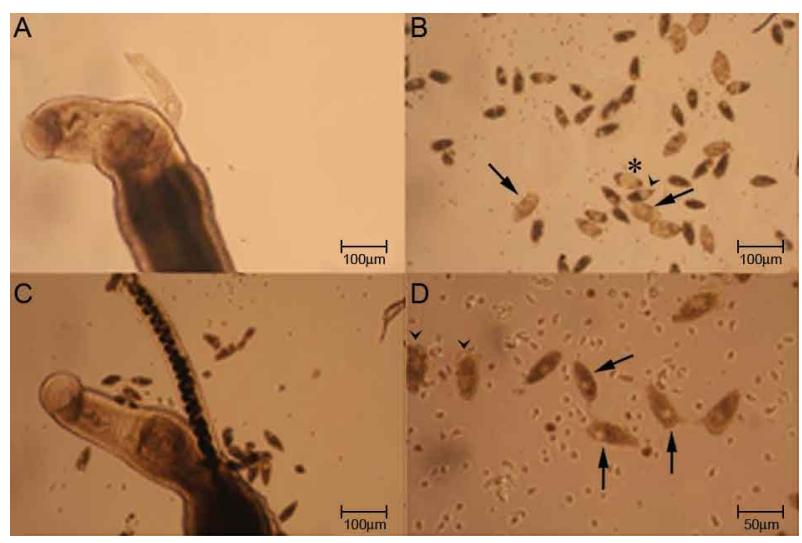

Fig. 1: evaluation of the in vitro activity of lovastatin on Schistosoma mansoni worms after a 7-day-culture period. A, B: control. A: adult paired worms without apparent morphological change; B: eggs at all stages; mature eggs (arrow), 3rd stage (head of the arrow), 4th stage (*); C: paired worms exposed to $2 \mu \mathrm{g} / \mathrm{ml}$ lovastatin and without apparent morphological change, and eggs at the 1st and 2nd stages; D: eggs laid by worms exposed to $4 \mu \mathrm{g} / \mathrm{ml}$ lovastatin; eggs at the 1 st stage (arrow) and dead (head of the arrow). i.e., eggs at the lst and 2 nd stages, or rarely at the 3 rd stage, were found dead at the end of the experiment, in the group exposed to $0.05 \mu \mathrm{g} / \mathrm{ml}$ lovastatin. On the other hand, in the control group, eggs at all the stages, including mature eggs, and hatched miracidia could be seen (Fig. 1). In the groups submitted to lovastatin at the concentrations of 2 and $4 \mu \mathrm{g} / \mathrm{ml}$, the 1st stage-eggs were not able to develop. After an 8-day-period of observation, the total number of morphologically dead eggs in the groups exposed to $2 \mu \mathrm{g} / \mathrm{ml}$ and $4 \mu \mathrm{g} / \mathrm{ml}$ lovastatin in vitro was $44(73.3 \%)$ and $348(94.8 \%)$, respectively; in the control group it was 144 (27.5\%). Using the probe Hoechst 33258, a fluorescent marker that label dead eggs (Sarvel et al 2006) it was observed that in the group exposed to $2 \mu \mathrm{g} / \mathrm{ml}$ lovastatin, $69 \%$ of the morphologically viable eggs were labeled by the probe, whereas in the group exposed to $4 \mu \mathrm{g} / \mathrm{ml}$ lovastatin, $74 \%$ of the eggs were labeled. In the control group, $16 \%$ of the morphologically viable eggs were labeled by the probe $(\mathrm{p}<0.05)$. The labeled eggs are shown in Fig. 2.

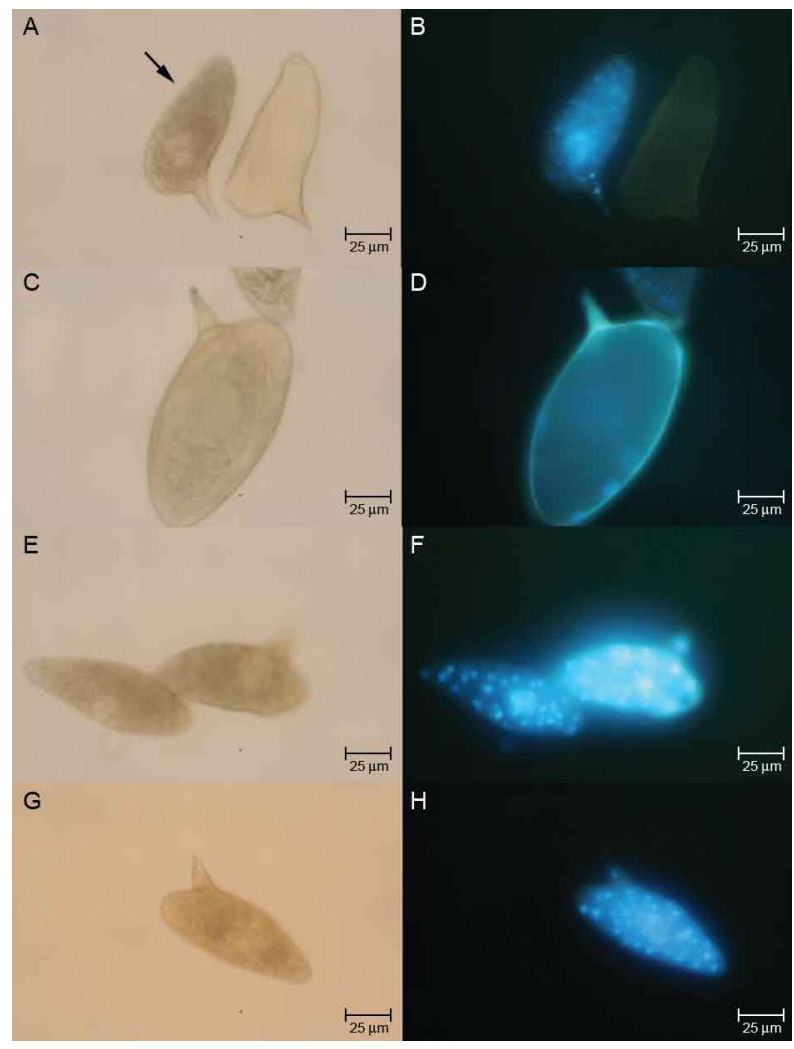

Fig. 2: classification of S. mansoni eggs by morphological (left) and fluorescent microscopy technique using the proble Hoechst 33258 (right). A-D: control, untreated worms; E-H: worms exposed to $2 \mu \mathrm{g} /$ $\mathrm{ml}$ or $4 \mu \mathrm{g} / \mathrm{ml}$ lovastatin in vitro for $24 \mathrm{~h}$. A: morphologically viable egg of the 1st stage and an empty egg (8-day-culture period); B: the same eggs with the embryo region clearly stained; considered as dead egg; C: morphologically viable mature egg (8-day-culture period); D: miracidium without labeling (alive egg); E: morphologically viable eggs of the 1st and 2nd stages (8-day-culture period) laid by treated worms; F: the same eggs both of them with the embryo region clearly stained (dead eggs); G: morphologically dead egg (8-day-culture period); H: the same egg totally labeled (dead egg). 
The worms obtained from mice treated with lovastatin $(400 \mathrm{mg} / \mathrm{kg} / \mathrm{day}$ for 5 days) and sacrificed three days after the end of treatment were cultured in vitro (in vivo/in vitro trials) in parallel with a group of worms exposed to $4 \mu \mathrm{g} / \mathrm{ml}$ lovastatin in vitro, as well as with a control group (worms not exposed to drug). Morphological changes could not be observed throughout the 8-dayculture, regarding the motion and egg-laying among the worms treated in vivo/ in vitro, as well as among the worms of the control group. In both cases, the eggs reached maturation, and hatching of miracidia could also be seen. The worms exposed to lovastatin in vitro presented results similar to those of the former experiment, as above mentioned.

\section{DISCUSSION}

Vandewaa et al. (1989) working with mevinolinate, farnesol and mevinolin, in vivo and in vitro, suggest that egg-production in schistosomiasis is associated with the activity of the enzyme 3-hydroxy 3-methylglutaryl coenzyme A (HMG-CoA) reductase, and that non-sterol lipids produced in biochemical metabolism, modulated by this enzyme, stimulate egg-production. Chen et al. (1990) observed that egg-laying by the parasite females was discontinued in mice infected with $S$. mansoni and treated with low doses of mevinolin. The administration of $0.2 \%$ mevinolin in the diet of infected mice (14 days) resulted in elimination of $96 \%$ of the parasites. The same dose administered two days before and 15 days pi resulted in $93-95 \%$ reduction in the number of adult parasites. When mevinolin was administered with $0.5 \%$ mevinolinate, there was inhibition of the anti-schistosomicidal activity of the former, suggesting that mevinolinate and/or metabolites are of the utmost importance for inhibiting $S$. mansoni eggproduction, as well as promoting the parasite's survival.

Lovastatin, a lactone, inactive form of the corresponding open hydroxylic acid, is a potent inhibitor of the endogenous synthesis of cholesterol. After gastrointestinal absorption, lovastatin is rapidly hydrolisated to open hydroxyacid, a competitive inhibitor of HMG-CoA reductase, an enzyme that catalyzes a regulatory step in the biosynthesis of cholesterol. In clinical studies (Araújo et al. 2002), lovastatin reduced the total plasmatic cholesterol concentrations and lipoprotein of low density, as well as lipoprotein of very low density bound to cholesterol.

Araújo et al. (2002) investigated the activity of lovastatin on the oviposition of the adult worm in experimentally infected mice with $S$. mansoni. These authors demonstrated that, despite the relatively low mortality rate $(\sim 30 \%)$ of the worms, when the beginning of treatment was on the 30th day pi, with an oral dose of $400 \mathrm{mg} / \mathrm{kg}$, for five consecutive days, there was a reduction in the oviposition of $S$. mansoni females, presenting oogram changes in up to $80 \%$ of mice, and an average number of eggs in the jejunum and liver significantly lower in the treated animals, when compared to the control group. The morphological analysis of the worms revealed degenerative changes, mainly in the reproductive apparatus of the worms, with reduction and alteration in the vitelline follicles and in the ovary of females, as well as changes in the male testis.
The role of cholesterol in schistosomiasis mansoni was experimentally evaluated by Neves (2006), using four groups of animals: infected, fed on a diet rich in cholesterol (29\% of lipids); infected, fed on a standard $\operatorname{diet}(12 \%$ of lipids); uninfected, fed on a diet rich in cholesterol; uninfected, fed on a standard diet. It was observed that infected mice that received a diet rich in cholesterol presented a higher number of viable $S$. mansoni eggs, a greater maturation and peak numbers of eggs in feces, when compared to the group of infected mice fed on a standard diet. It was also observed that the adult worms recovered from the group of infected mice fed on a diet rich in cholesterol (29\% lipids) presented a higher number of morphological changes in the reproductive apparatus of male worms, mainly in relation to supranumerary lobe, seminal vesicle and spermatheca. In this group, the ovary of females presented a higher number of oocytes being discharged than in females belonging to the group with $12 \%$ lipids in the diet. It seems that a site rich in cholesterol is beneficial for reproduction and discharge of S. mansoni eggs (Neves 2006).

Soliman \& Ibrahim (2005) studied the activity of atorvastatin (cholesterol lowering agent) alone, and concurrently with medoxyprogesterone (intramuscular contraceptive) on S. haematobium adult worms, in experimentally infected hamsters. Atorvastatin administered by oral route, at the dose of $0.9 \mathrm{mg} / \mathrm{kg}$ starting from day $35 \mathrm{pi}$, for 49 consecutive days, and with medoxyprogesterone acetate in association, at the dose of $0.1 \mathrm{ml} / \mathrm{kg}$ on days seven and $35 \mathrm{pi}$, intramuscularly, produced damages in the tegument of male and female worms. Loss or rupture of tubercles, collapse of tissues, and erosion of the tegument and of the oral suckers, degenerations or collapses of sensorial organelles, were some of the observed changes. Administration of atorvastatin alone, according to the same schedule previously described, produced less severe damages in the tegument of male worms, and only a few females presented tegumental changes. Both treatment schedules (atorvastatin concurrently with medoxyporogesterone acetate or alone) contributed to a significant reduction in the total number of recovered worms, $46.2 \%$ and $51.3 \%$, respectively. The two drugs in association produced oogram changes, with a high number of dead eggs.

In the present work, in vivo assays showed that lovastatin acted on $S$. mansoni egg-laying, initially by decreasing in the presence of egg in the female uterus, and after that by oogram changes. These results were observed not only in the animals treated with lovastatin alone, but also when this drug was administered concurrently with oxamniquine. In vitro trials showed that maturation of eggs was not complete due to the action of lovastatin, being interrupted at the 1st or 2nd stages, according to the dose used. On the other hand, those eggs discharged by females of the control group developed normally, passing through all the stages, reaching maturation and culminating with miracidium hatching. The complete process of egg maturation was also observed when worms were recovered from mice treated with lovastatin and cultured in vitro. The exposure of worms to lovastatin in vitro is necessary to obtain the blockage of egg development. Additionally, the viabil- 
ity of $S$. mansoni eggs showed a significant difference when a fluorescent probe was used. In fact, the average of morphologically viable eggs, labeled by the probe, was $70 \%$ approximately in the groups exposed to $2 \mu \mathrm{g} /$ $\mathrm{ml}$ or $4 \mu \mathrm{g} / \mathrm{ml}$ lovastatin. In the control group, it was observed that only $16 \%$ of the morphologically viable eggs were labeled by the probe. Since egg labeling by the probe indicates that the egg is dead, the difference in the classification of viable eggs is evident when the probe is used in comparison when only the morphology of the egg is observed under an optic microscope. When applied in assays without drug utilization, the methodology recommended by Sarvel et al. (2006) with the aim to confirm the traditional morphological classification, $83 \%$ of corroboration between the two methods was detected. Nevertheless, in the trials related to drug activity was much lower (30\%), i.e., only 10 out of 35 morphologically viable eggs present in the groups exposed to $2 \mu \mathrm{g} / \mathrm{ml}$ or $4 \mu \mathrm{g} / \mathrm{ml}$ lovastatin were not labeled by the probe. The use of the probe Hoechst 33258 enhances the sensitivity of the trials aiming to evaluate drug action on viable $S$. mansoni eggs.

The data obtained corroborate the action of lovastatin in S. mansoni egg-laying, in both in vivo and in vitro experiments. Nevertheless, the synergistic or additive schistosomicidal action of this drug concurrently with other known antischistosomal drugs (oxamniquine or praziquantel) could not be observed.

\section{ACKNOWLEDGEMENT}

To Dr. John R. Kusel for his suggestions and review of the manuscript.

\section{REFERENCES}

Araujo N, Kohn A, Oliveira AA, Katz N 2002. Schistosoma mansoni: ação da lovastatina no modelo murino. Rev Soc Bras Med Trop 35: $35-38$.
Chen GZ, Foster L, Bennett JL 1990. Antischistosomal action of mevinolin evidence that 3-hydroxy-methylglutaryl-coenzime a reductase activity Schistosoma mansoni is vital for parasite survival. Naunyn Schmiedebergs Arch Pharmacolol 342: 477-482.

Doenhoff MJ, Kussel JR, Coles GC, Cioli D 2002. Resistance of Schistosoma mansoni to praziquantel: is there a problem? Trans R Soc Trop Med Hyg 96: 465-469.

Katz N 1980. Experiência com quimioterapia em grande escala no controle da esquistossomose no Brasil. Rev Inst Med Trop Sao Paulo 22: 40-51.

Neves RH 2006. Avaliação do papel da dieta rica em colesterol na esquistossomose mansônica experimental de Mus musculus Swiss Webster, PhD Thesis, Instituto Oswaldo Cruz, Rio de Janeiro, 161 pp.

Pellegrino J, Oliveira CA, Faria J, Cunha AS 1962. New approach to screening of drugs in experimental Schistosomiasis mansoni in mice. Am J Trop Med Hyg 11: 201-215.

Pellegrino J, Siqueira AF 1956. Técnica de perfusão para colheita de Schistosoma mansoni em cobaias experimentalmente infestadas. Rev Bras Malariol Doenças Trop 8: 589-597.

Sarvel AK, Kusel JR, Araujo N, Coelho PMZ, Katz N 2006. Comparison between morphological and staining characteristics of live and dead eggs of Schistosoma mansoni. Mem Inst Oswaldo Cruz 101 (Suppl. I): 289-292.

Smithers SR, Terry RJ 1965. The infection of laboratory hosts with cercariae of Schistosoma mansoni and the recovery of adults worms. Parasitology 55: 695-700.

Soliman MFM, Ibrahim MM 2005. Antischistosomal action of atorvastatin alone and concurrently with medroxyprogesterone acetate on Schistosoma haematobium harboured in hamster: surface ultraestructure and parasitological study. Acta Trop 93: 1-9.

Vandewaa EA, Mills G, Foster LA, Bennett JL 1989. Physiological role of HGM-CoA reductase in regulating egg production by Schistosoma mansoni. Am J Physiol 257: 618-625. 